\title{
The impact of the pandemic influenza A(H1N1) 2009 virus on seasonal influenza $A$ viruses in the southern hemisphere, 2009
}

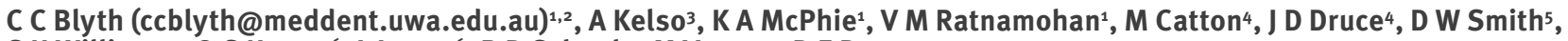
S H Williams', Q S Huang ${ }^{6}$, L Lopez ${ }^{6}$, B D Schoub7, M Venter7, D E Dwyer $^{1}$

1. Centre for Infectious Diseases and Microbiology Laboratory Services, Institute of Clinical Pathology and Medical Research (ICPMR), Westmead Hospital, Westmead, New South Wales, Australia

2. School of Paediatrics and Child Health, University of Western Australia, Princess Margaret Hospital, Subiaco, Western

Australia, Australia

3. World Health Organisation Collaborating Centre for Reference and Research on Influenza, Victorian Infectious Diseases

Reference Laboratory (VIDRL), North Melbourne, Victoria, Australia

4. Victorian Infectious Diseases Reference Laboratory, North Melbourne, Victoria, Australia

5. Pathwest Laboratory Medicine, Queen Elizabeth II Medical Centre, Nedlands, Western Australia, Australia

6. World Health Organisation National Influenza Centre, Institute of Environmental Science and Research, Wellington, New

Zealand

7. National Institute for Communicable Diseases, Sandringham, Johannesburg, South Africa

Citation style for this article:

Blyth CC, Kelso A, McPhie KA, Ratnamohan VM, Catton M, Druce JD, Smith DW, Williams SH, Huang QS, Lopez L, Schoub BD, Venter M, Dwyer DE. The impact of the pandemic influenza $A\left(\mathrm{H}_{1} N_{1}\right) 2009$ virus on seasonal influenza A viruses in the southern hemisphere, 2009. Euro Surveill. 2010;15(31):pii=19631. Available online: http://www.eurosurveillance.org/ViewArticle.aspx?Articleld=19631

Article published on 5 August 2010

Data collected over winter 2009 by five World Health Organisation National Influenza Centres in the southern hemisphere were used to examine the circulation of pandemic and seasonal influenza A strains during the first pandemic wave in the southern hemisphere. There is compelling evidence that the pandemic influenza $A\left(\mathrm{H}_{1} \mathrm{~N}_{1}\right) 2009$ virus significantly displaced seasonal influenza $A\left(\mathrm{H}_{1} \mathrm{~N}_{1}\right)$ and, to a lesser extent, $A\left(\mathrm{H}_{3} \mathrm{~N}_{2}\right)$ viruses circulating in the southern hemisphere. Complete replacement of seasonal influenza A strains, however, was not observed during the first pandemic wave.

\section{Introduction}

Historically influenza pandemics have been associated with replacement of the previously circulating influenza A subtype, as was observed in 1957 when influenza $A\left(H_{2} N_{2}\right)$ replaced $A\left(H_{1} N_{1}\right)$, and in 1968 when influenza $A\left(\mathrm{H}_{3} \mathrm{~N}_{2}\right)$ subsequently replaced $A\left(\mathrm{H}_{2} \mathrm{~N}_{2}\right)$. As global viral surveillance was limited during the pandemics of 1957 and 1968, the proportion of disease attributable to seasonal influenza viruses during the early pandemic periods and the rate of subtype replacement are uncertain. It is postulated that cross-protective immunity following infection with a pandemic influenza virus results in protection against circulating seasonal influenza subtypes. This protection results in displacement and replacement of seasonal influenza subtypes by pandemic viruses [1-3]. Co-existence of different subtypes is possible when the introduction of a virus does not generate a pandemic. The reintroduction of an influenza virus in a context of considerable residual herd immunity, as was observed with influenza $\mathrm{A}\left(\mathrm{H}_{1} \mathrm{~N}_{1}\right)$ in 1977 , can result in co-circulation of more than one influenza subtype $[1,3]$. We cannot be certain whether emerging pandemic influenza strains will replace or co-exist with the previously circulating subtypes or strains, and if replacement is observed, how quickly this will occur. As this outcome has implications on the selection of viruses to be included in influenza vaccines, improved surveillance and rapid influenza A subtyping methods have important roles to play in monitoring the circulation dynamics of influenza strains during modern epidemics and pandemics.

The pandemic influenza $A\left(\mathrm{H}_{1} \mathrm{~N}_{1}\right) 2009$ virus was first identified in April 2009 [4-6]. As its detection in the northern hemisphere coincided with declining seasonal influenza activity, the impact on the circulation of seasonal influenza viruses could not be fully assessed [7]. In contrast, the first wave of the pandemic influenza virus in the southern hemisphere coincided with the onset of the winter influenza and respiratory virus season. Thus, data obtained from the 2009 southern hemisphere winter provide an opportunity to examine the circulation dynamics of pandemic and seasonal viruses during the early pandemic period.

This report presents data obtained by five World Health Organization (WHO) National Influenza Centres in the southern hemisphere for the winter of 2009. The pattern of circulating pandemic and seasonal influenza A strains in the southern hemisphere provides important information that can contribute to decision making regarding vaccine strain selection, and preventative and therapeutic strategies. 


\section{Methods}

Influenza A subtyping data from all diagnostic respiratory tract specimens submitted in winter 2009 to five WHO National Influenza Centres (NICs) in Australia, New Zealand and South Africa were collated and analysed. NICs in Melbourne, Sydney and Perth receive samples from the Australian states of Victoria, New South Wales and Western Australia, respectively, whereas NICs in Wellington and Johannesburg receive the samples from across New Zealand and South Africa, respectively.

Influenza detection and subtyping was performed within each laboratory by nucleic acid testing using polymerase chain reaction (PCR) of type-specific targets within the matrix gene and subtype-specific targets within the haemagglutinin gene regions of the influenza virus genome. To assist with interpretation of the raw data, samples that tested positive for influenza $A$ yet were not subtyped were removed prior to analysis. Where available, the PCR-positive detection rates from respiratory samples received during previous seasons (examined in similar populations using similar surveillance methods) were compared with those from the 2009 season.

\section{Results}

Influenza A was detected by PCR in 17,328 respiratory tract specimens collected at the five NICs from May to October 2009 (week 18 to week 44). Influenza A subtyping was available for $90 \%$ of influenza A positive specimens (Wellington: $73 \%$; Melbourne: $95 \%$, Sydney: $89 \%$, Perth: $100 \%$, Johannesburg: $97 \%$ ). The number of typed and untyped specimens as a proportion of total positive tests remained consistent in all centres across the study period. Epidemic curves from the five NICs were constructed (Figure 1). Data were expressed as a proportion of total tests positive for influenza by PCR (Figure 2) and as a proportion of total tests performed (Figure 3).

Pandemic influenza $A\left(\mathrm{H}_{1} \mathrm{~N}_{1}\right) 2009$ activity in the southern hemisphere was first detected in New Zealand in week 18 (peak activity in week 28), followed by Melbourne, Sydney and Perth in week 21 (peak activity in weeks 22, 25 and 29 respectively) and then South Africa in week 25 (peak activity in week 32) (Figure 1). Significant pandemic influenza activity was detected in all locations: The overall proportion of influenza A-positive specimens from May to October 2009 subtyped as pandemic influenza $\mathrm{A}\left(\mathrm{H}_{1} \mathrm{~N}_{1}\right) 2009$ was $78 \%$ in Wellington, $85 \%$ in Melbourne, $80 \%$ in Sydney, $89 \%$ in Perth and $53 \%$ in Johannesburg (Figures 2 and 3 ). The proportion of influenza viruses typed as pandemic influenza $A\left(\mathrm{H}_{1} \mathrm{~N}_{1}\right) 2009$ following first identification of the pandemic virus was $78 \%$ in Wellington, $85 \%$ in Melbourne, $80 \%$ in Sydney, $90 \%$ in Perth and $68 \%$ in Johannesburg. These proportions increased to $93 \%$, $95 \%, 92 \%, 96 \%$ and $94 \%$, respectively, if only those specimens received during the second half of the pan-

\section{FIGURE 1}

Number of positive influenza specimens per week, by subtype, southern hemisphere, weeks 18-44, 2009

$-\mathrm{A} / \mathrm{H}_{1} \mathrm{~N}_{1}$ (Seasonal) $-\mathrm{A} / \mathrm{H}_{1} \mathrm{~N}_{109}-\mathrm{A} / \mathrm{H}_{3} \mathrm{~N}_{2}$
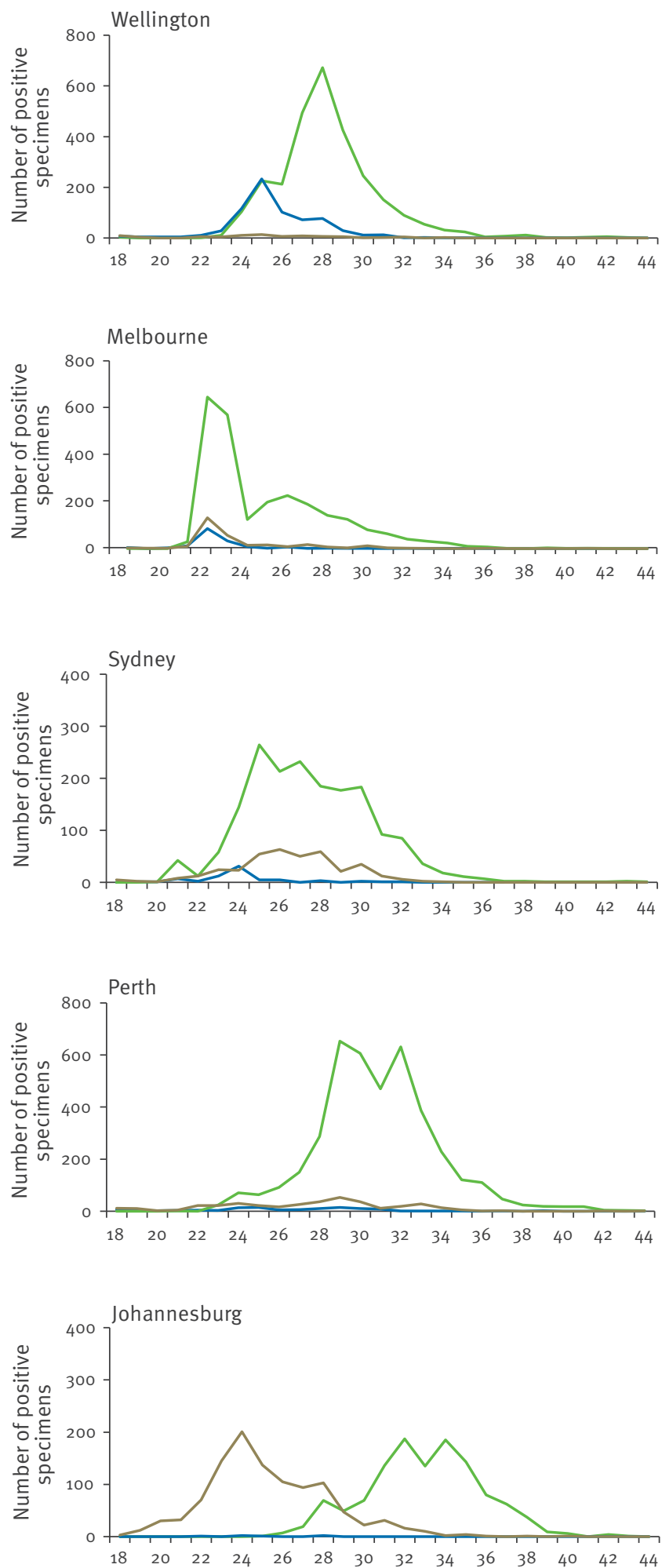

Week 2009

Note: untyped specimens have been excluded from graphs and analysis. 


\section{FIGURE 2}

Proportion of positive influenza tests, by subtype, southern hemisphere, weeks 18-44, 2009

$\square \mathrm{A} / \mathrm{H}_{1} \mathrm{~N}_{1}$ (Seasonal) $\square \mathrm{A} / \mathrm{H}_{1} \mathrm{~N}_{109} \square \mathrm{A} / \mathrm{H}_{3} \mathrm{~N}_{2}$
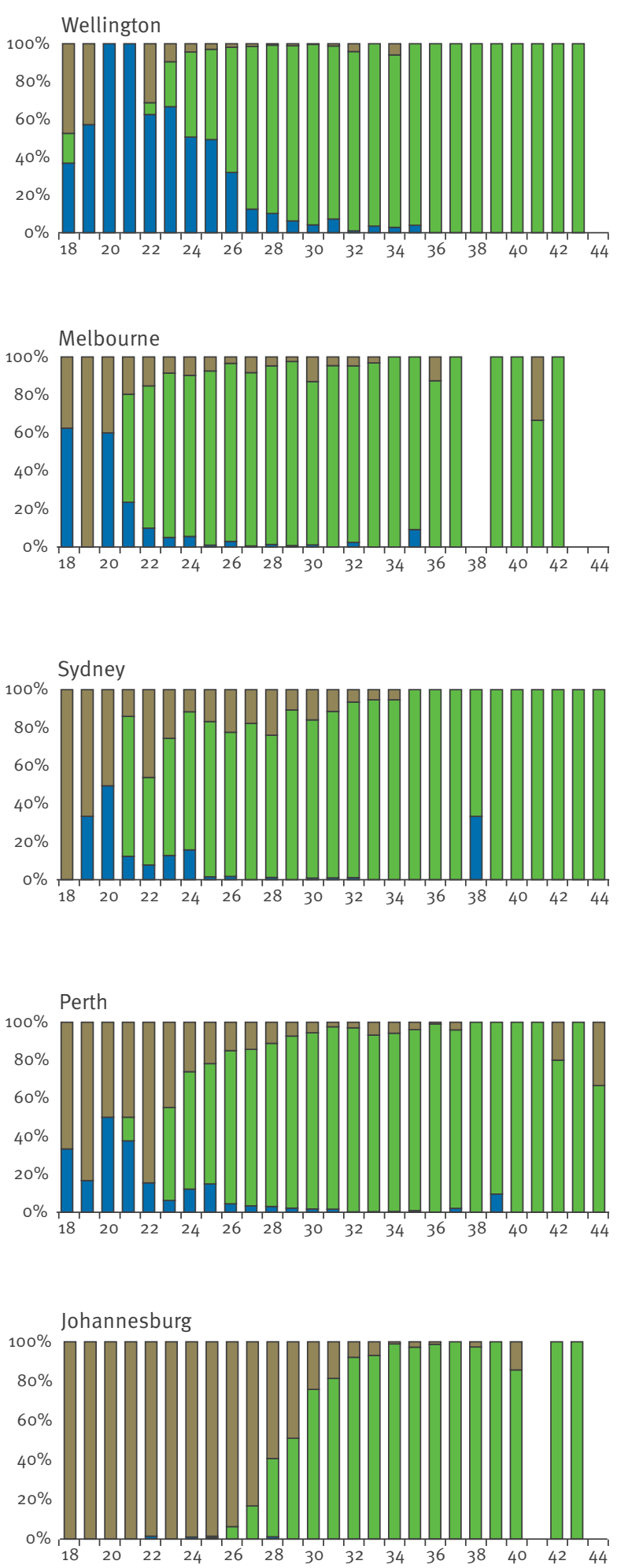

Week 2009

Note: untyped specimens have been excluded from graphs and analysis.

\section{FIGURE 3}

Positive influenza specimens as a proportion of all tests, by subtype, southern hemisphere, weeks 18-44 2009

$\square \mathrm{A} / \mathrm{H}_{1} \mathrm{~N}_{1}$ (Seasonal) $\square \mathrm{A} / \mathrm{H}_{1} \mathrm{~N}_{109} \square \mathrm{A} / \mathrm{H}_{3} \mathrm{~N}_{2}$
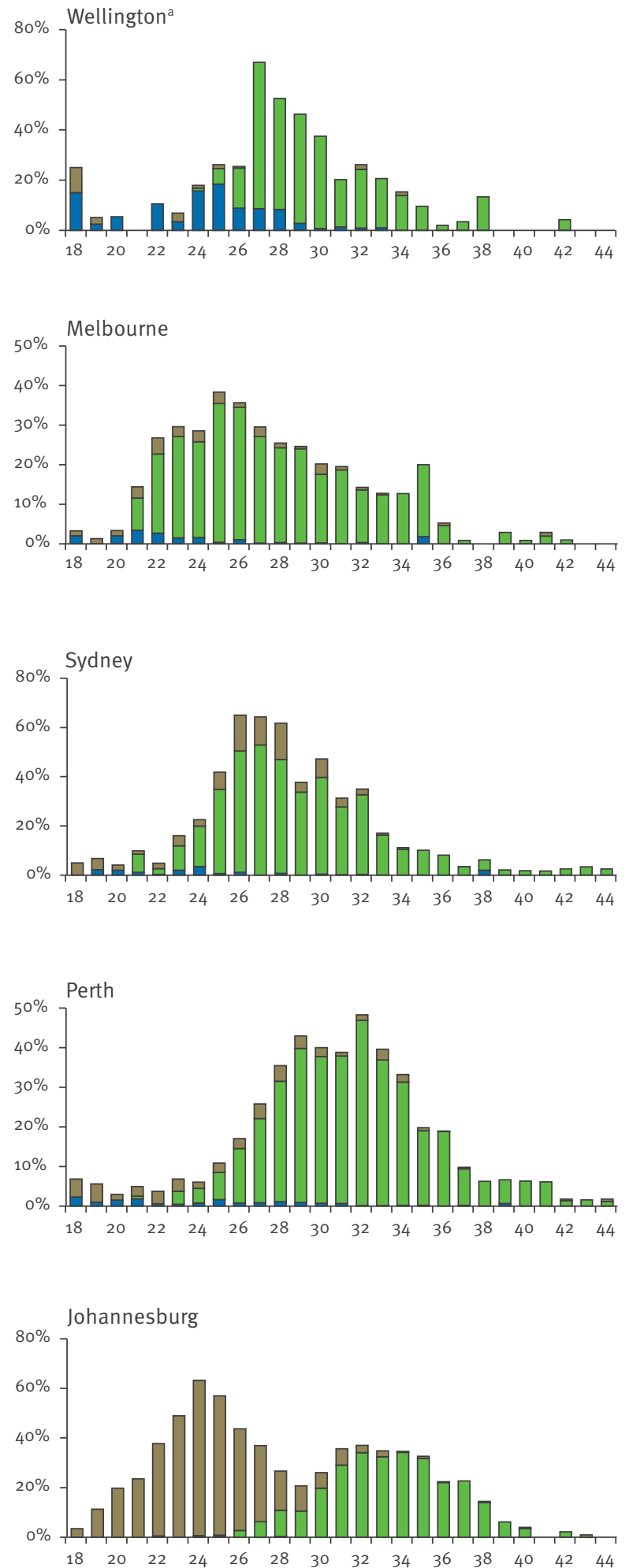

Week 2009

Note: untyped specimens have been excluded from graphs and analysis.

a Wellington data obtained from sentinel surveillance only. 
demic from August to October 2009 (week 31 to week 44 ) were examined independently.

Seasonal influenza A activity coincided with pandemic influenza activity in New Zealand, and preceded it in Australia and South Africa. Total seasonal influenza virus activity was generally modest. Twenty per cent of PCR-positive specimens were subtyped as seasonal influenza $\mathrm{A}\left(\mathrm{H}_{1} \mathrm{~N}_{1}\right)$ in Wellington, $5 \%$ in Melbourne, $3 \%$ in Sydney, $2 \%$ in Perth and less than $1 \%$ in Johannesburg. The corresponding figures for influenza $\mathrm{A}\left(\mathrm{H}_{3} \mathrm{~N}_{2}\right)$ were $2 \%$ in Wellington, $10 \%$ in Melbourne, $17 \%$ in Sydney, $8 \%$ in Perth and $47 \%$ in Johannesburg (Figure 3). Despite the low levels in most catchment areas, both seasonal influenza $A\left(\mathrm{H}_{1} \mathrm{~N}_{1}\right)$ and $A\left(\mathrm{H}_{3} \mathrm{~N}_{2}\right)$ activity were detected in all three countries throughout the winter 2009.

Samples from sentinel general practitioner surveillance systems provide the best estimate of community influenza activity. The 2009 influenza season was compared with previous seasons using sentinel data from the NICs in Wellington, Melbourne and Perth, each of which receives samples from country-wide (Wellington) or state-wide (Melbourne, Perth) surveillance systems operating during the winter influenza season. In 2009, $27-35 \%$ of surveillance specimens were influenza A-positive compared to $20-39 \%$ in 2007 and $13-27 \%$ in 2008 (Figure 4). Pandemic influenza $A\left(\mathrm{H}_{1} \mathrm{~N}_{1}\right) 2009$ virus was identified in $71-98 \%$ of influenza PCR-positive samples in 2009. The absolute number and proportion of samples positive for seasonal influenza viruses (Figure 4; dark blue) in all three locations was lower in 2009 compared with the previous two seasons.

\section{Discussion and conclusions}

The impact of the pandemic influenza $A\left(\mathrm{H}_{1} \mathrm{~N}_{1}\right) 2009$ virus on circulating seasonal influenza strains was demonstrated using data obtained by five WHO National Influenza Centres in the southern hemisphere in the winter of 2009. Examination of influenza strains as a proportion of the subtyped influenza A positive

\section{FIGURE 4}

Proportion of submitted respiratory samples PCR-positive for influenza, by year and influenza subtype, sentinel general practitioner surveillance data (Wellington, Melbourne, Perth), 2007-2009

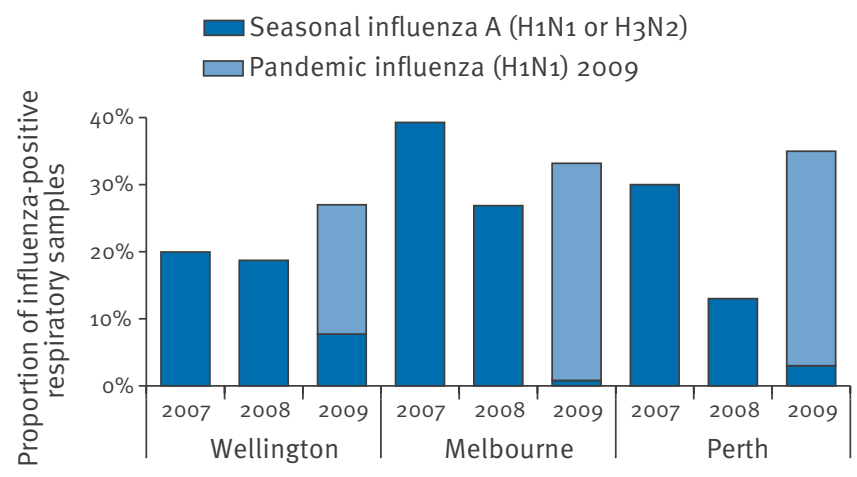

specimens in 2009 (Figure 2), total test specimens in 2009 (Figure 3) and 2007-2009 sentinel surveillance specimens (3 sites only, Figure 4) provides compelling evidence that the pandemic virus significantly displaced seasonal influenza viruses. Consistently across Australia, New Zealand and South Africa, the replacement was rapid and progressive with seasonal strains comprising a low and declining proportion of influenza A detections from the peak of the pandemic wave through to the end of the season. Complete seasonal influenza A strain replacement, however, was not observed. These data are consistent with data presented by Tang et al. when examining 2009 influenza activity in Singapore [2]. Raw data and the shape of epidemic curves need to be interpreted with caution given the impact of testing behaviour (particularly elevated testing at the beginning of the pandemic) and modifications of testing algorithms through the course of the season (e.g. Figure 1, Melbourne).

The reduction in seasonal influenza $A\left(\mathrm{H}_{1} \mathrm{~N}_{1}\right)$ activity was the most obvious effect of the 2009 pandemic. Significant early activity of seasonal influenza $\mathrm{A}\left(\mathrm{H}_{1} \mathrm{~N}_{1}\right)$ was observed in New Zealand and, to a lesser extent, Australia. Following the entry of the pandemic virus, detection of seasonal $\mathrm{A}\left(\mathrm{H}_{1} \mathrm{~N}_{1}\right)$ viruses quickly decreased and remained at low levels throughout the winter. The majority of tested seasonal influenza $A\left(H_{1} N_{1}\right)$ viruses were resistant to oseltamivir (A Kelso, unpublished data), as observed in the previous northern hemisphere winter. Seasonal influenza $A\left(\mathrm{H}_{3} \mathrm{~N}_{2}\right)$ activity also declined as the pandemic progressed, but the effect was less obvious and activity continued at higher levels than those of seasonal influenza $A\left(\mathrm{H}_{1} \mathrm{~N}_{1}\right)$ throughout the season.

A similar observation was made in North America in 2009. While the absolute numbers of detected seasonal influenza viruses increased in the United States (US) from April to May 2009, the proportion of specimens positive for seasonal influenza strains continued to decrease during this time [7]. This increase in absolute numbers yet decrease in the proportion of positive specimens is likely to reflect an increase in the number of influenza tests performed [7]. The 2009-2010 winter data from the US WHO and National Respiratory and Enteric Virus Surveillance System (NREVSS) Collaborating Laboratories demonstrated that, although more than $99 \%$ of reported influenza A-positive tests were subtyped as pandemic influenza $A\left(\mathrm{H}_{1} \mathrm{~N}_{1}\right) 2009$, ongoing transmission of seasonal strains was detected [8].

Given the high mutation rate and continual emergence of novel genetic lineages of influenza virus, it remains uncertain why pandemic influenza viruses replace existing seasonal influenza A subtypes and strains. Transient heterosubtypic immunity - short-lived immunity which is cross-protective against different subtypes and declines rapidly over time - has been shown to inhibit re-infection by any new strain in animal 
models $[1,9,10]$. It is postulated that, during pandemics, a substantial fraction of the global population is infected with the new virus and is then transiently immune to infection with the previously circulating subtypes [3]. This leaves a critically low number of susceptible individuals, leading to the extinction of seasonal influenza strains. It is important to note that the effect is specific for influenza $A$ viruses as the replacement of circulating influenza B virus lineages is not observed.

Data from both the 2009 southern hemisphere and 2009-2010 northern hemisphere influenza season $[7,8]$ suggest that pandemic influenza $A\left(\mathrm{H}_{1} \mathrm{~N}_{1}\right) 2009$ will be the predominant influenza A strain in the 2010 influenza season in the southern hemisphere. Whether complete subtype replacement will be observed in 2010 remains uncertain. These data support the recommendation that seasonal influenza vaccines for the southern hemisphere in 2010 and the northern hemisphere in 2010-2011 contain representative pandemic influenza $A\left(\mathrm{H}_{1} \mathrm{~N}_{1}\right)$ and seasonal influenza $A\left(\mathrm{H}_{3} \mathrm{~N}_{2}\right)$ viruses (as well as an influenza $B$ virus) [11], but not the previously circulating seasonal influenza $A\left(\mathrm{H}_{1} \mathrm{~N}_{1}\right)$ virus. Given the evidence of ongoing, albeit sporadic, transmission of seasonal influenza A viruses eleven months after pandemic influenza was first detected, it is likely that influenza $\mathrm{A}\left(\mathrm{H}_{3} \mathrm{~N}_{2}\right)$ and perhaps also seasonal influenza $A\left(\mathrm{H}_{1} \mathrm{~N}_{1}\right)$ infections will be observed during the coming season. Whether ongoing suppression of seasonal viruses will lead to complete replacement remains to be determined.

\section{Acknowledgements}

The authors would like to thank the Melbourne WHO Collaborating Centre for Reference and Research on Influenza for their assistance with influenza subtyping and analyses. The Melbourne WHO Collaborating Centre for Reference and Research on Influenza is supported by the Australian Government Department of Health and Ageing.

\section{References}

1. Ferguson NM, Galvani AP, Bush RM. Ecological and immunological determinants of influenza evolution. Nature. 2003:422(6930):428-33.

2. Tang JW, Lee CK, Lee HK, Loh TP, Chiu L, Tambyah PA, et al. Tracking the emergence of pandemic Influenza A/H1N1/2009 and its interaction with seasonal influenza viruses in Singapore. Ann Acad Med Singapore. 2010;39(4):291-4.

3. Ferguson NM, Bush RM. Influenza evolution and immune selection. International Congress Series. 2004;1263:12-6.

4. Novel Swine-Origin Influenza $A\left(\mathrm{H}_{1} \mathrm{~N}_{1}\right)$ Virus Investigation Team, Dawood FS, Jain S, Finelli L, Shaw MW, Lindstrom S, et al. Emergence of a novel swine-origin influenza $A\left(\mathrm{H}_{1} \mathrm{~N}_{1}\right)$ virus in humans. N Engl J Med. 2009;360(25):2605-15.

5. Centers for Disease Control and Prevention. Outbreak of swineorigin influenza A H1N1) virus infection - Mexico, March-April 2009. MMWR Morb Mortal Wkly Rep. 2009;58(17):467-70

6. World Health Organisation (WHO). Swine influenza - update 4. Disease Outbreak News. Geneva: WHO; 28 April 2009. Available from: http://www.who.int/csr/don/2009_04_28/en/ index.html

7. Centers for Disease Control and Prevention (CDC). FluView. 2008-2009 influenza season week 39 ending October 3, 2009 [Accessed 26 February 2009]; Atlanta: CDC; 2009. Available from: http://www.cdc.gov/flu/weekly/ weeklyarchives2008-2009/weekly39.htm
8. Centers for Disease Control and Prevention (CDC). FluView. 2009-2010 influenza season week 6 ending February 13, 2010. [Accessed 26 February 2009]. Atlanta: CDC; 2009. Available from: http://www.cdc.gov/flu/weekly/ weeklyarchives2009-2010/weeklyo6.htm

9. Grebe KM, Yewdell JW, Bennink JR. Heterosubtypic immunity to influenza A virus: where do we stand? Microbes Infect. 2008;10(9):1024-9.

10. Schulman JL, Kilbourne ED. Induction of partial specific heterotypic immunity in mice by a single infection with influenza A virus. J Bacteriol. 1965;89:170-4.

11. World Health Organisation (WHO). Recommendations for influenza vaccines. [Accessed 22 February 2010]. Geneva: WHO Available from: http://www.who.int/csr/disease/influenza/ vaccinerecommendations/en/index.html 